\title{
ARTICLES
}

\section{Co-Inoculation of Prostate Cancer Cells With U937 Enhances Tumor Growth and Angiogenesis In Vivo}

\author{
Matthew Craig, ${ }^{1}$ Chi Ying, ${ }^{1}$ and Robert D. Loberg ${ }^{1,2 *}$ \\ ${ }^{1}$ Department of Urology, University of Michigan, Ann Arbor, Michigan \\ ${ }^{2}$ Department of Internal Medicine, University of Michigan, Ann Arbor, Michigan
}

\begin{abstract}
Tumor-associated macrophages (TAMs) have been implicated in promoting tumor growth and development. Here we present evidence that demonstrates that co-inoculation of male athymic nude mice with PC-3 prostate cancer cells and U937 promonocytic cells enhances tumor growth and increases tumor angiogenesis. Male athymic nude mice were co-inoculated with PC-3 and U937 cells (control or IL-4 stimulated) and tumor growth was monitored over time. Immunohistochemical analysis of tumor specimens was performed for proliferation markers (e.g., Ki67) and the effects of IL-4 stimulation on U937 cells were analyzed for chemokine expression. The presence of $U 937$ cells increased the rate of tumor growth in vivo and stimulated increased microvascular density within the tumor bed. Stimulation of $U 937$ cells with IL-4 resulted in a significant increase in several pro-angiogenic and pro-tumor chemokines (e.g., CCL2). Co-inoculation increases prostate cancer growth via upregulation of chemokines that induce angiogenesis within the tumor. J. Cell. Biochem. 103: 1-8, 2008. @ 2007 Wiley-Liss, Inc.
\end{abstract}

Key words: tumor associated macrophage; interleukin 4; chemokine

The role of tumor-associated macrophages (TAMs) in prostate cancer metastasis has not been well investigated. Macrophages can be "polarized" towards one of two phenotypically different subsets of macrophages: $\mathrm{T}_{\mathrm{H}} 1$ (also known as $\mathrm{M} 1$ macrophage) or $\mathrm{T}_{\mathrm{H}} 2$ (also known as M2 macrophage) [Sica et al., 2006]. M1 macrophages are known to produce pro-inflammatory cytokines and play an active role in cell destruction while M2 macrophages primarily scavenge debris and promote angiogenesis and wound repair [Sica et al., 2006]. Recently, the M2 macrophage population is thought to be phenotypically similar to the TAM population that promotes tumor growth and development. Recently, we have reported the role of CCL2 (monocyte chemoattractant protein 1; MCP-1) in prostate cancer growth in vitro [Loberg et al.,

Grant sponsor: NIH; Grant number: 5P50CA069568.

*Correspondence to: Robert D. Loberg, Ph.D., University of Michigan, 7312 CCGC, 1500 E. Medical Center Dr., Ann Arbor, MI 48109-0946. E-mail: rloberg@umich.edu

Received 15 January 2007; Accepted 20 March 2007

DOI 10.1002/jcb.21379

(c) 2007 Wiley-Liss, Inc. 2006a]. CCL2, as well as CCL7 and CCL8, is an important chemokine that is known to regulate monoctye/macrophage trafficking and has been reported to be present in several solid tumor beds [Negus et al., 1997; Kelly et al., 1998; Van Damme et al., 2004]. The mechanism that induces the biological change from a tumor destructive macrophage to a tumor promoting TAM is not understood. Several hypotheses have been suggested including alternative cytokine release from the tumor cells that induces a phenotypic switch in the macrophage population. Interleukin 4 (IL-4) has been implicated as an important cytokine inducing the differentiation of classical macrophages into alternative macrophages [Hart et al., 1999]. The role of IL-4 in regulating the differentiation of monocytes/ macrophages into TAMs in prostate cancer has not been reported. Here we present evidence that demonstrates that co-inoculation of male athymic nude mice with PC-3 prostate cancer cells and U937 promonocytic cells enhance tumor growth and increases tumor angiogenesis. Further, stimulation of U937 cells with IL-4 prior to inoculation enhanced tumor growth in vivo and stimulated angiogenesis within the tumor bed. 


\section{MATERIALS AND METHODS}

\section{Reagents}

Human Recombinant Interlukin-4 (hrIL-4) was obtained from R\&D systems; Drabkin's Reagent, containing Potassium Ferricyanide, Potassium Cyanide, and Sodium Bicarbonate, was obtained from RICAA Chemical Company.

\section{Cell Culture}

U-937 cells are a promonocytic cell line purchased from ATCC and can be induced to terminal monocytic differentiation phorbol esters [Sundstrom and Nilsson, 1976]. U-937 cells and PC-3 prostate cancer cell lines were maintained in RPMI 1,640 +10\% fetal bovine serum (FBS). HDMVEC cells were maintained in complete endothelial cell growth medium + $10 \%$ FBS. U937 cells were grown in suspension and were split for passaging while PC-3 cells and HDMVEC cells were passaged by trypsinization using $1 \times$ Trypsin + EDTA (Invitrogen Corp., Carlsbad, CA), resuspended in appropriate growth medium, and used within 10 passages of each other for consistency. Peripheral blood mononuclear cells (PBMCs) were isolated from peripheral blood from a 33-year-old healthy male. Monocytes were isolated using CD14+ magnetic bead selection (Miltenyi, Inc.) IL-4 stimulated U937 cells (U937 ${ }^{\mathrm{IL}-4}$ ) were incubated in SF RPMI + IL-4 at a concentration of $10 \mathrm{ng} / \mathrm{ml}$ for $72 \mathrm{~h}$. All cell lines were incubated at $37^{\circ} \mathrm{C}$ in $5 \% \mathrm{CO}_{2}$.

\section{Xenograft Model of Tumorigenesis}

Xenograft tumors were established as previously described [Loberg et al., 2006b]. Briefly, male athymic mice (5-6 weeks) were injected subcutaneously with $1 \times 10^{5} \mathrm{PC}-3$ cells with or without $1 \times 10^{4} \mathrm{U} 937$ cells or $1 \times 10^{4} \mathrm{U} 3^{\mathrm{IL}-4}$ cells in $200 \mu \mathrm{l}$ Matrigel (BD Biosciences, Inc.). A second group of male athymic mice ( $5-6$ weeks) were injected subcutaneously with $1 \times 10^{5} \mathrm{PC}-3$ cells with or without $1 \times 10^{4}$ PBMCs or $1 \times 10^{4}$ $\mathrm{PBMCs}^{\mathrm{IL}-4}$ cells in $200 \mu \mathrm{l}$ Matrigel (BD Biosciences, Inc.). Four mice were assigned to each group. Tumor volumes were calculated by caliper measurement performed weekly to monitor and track tumor growth (tumor volume $=\mathrm{L} \times \mathrm{W} \times \mathrm{W} \times 0.56$ ). Tumors were harvested once the tumor reached the predefined critical mass of $1,000 \mathrm{~mm}^{3}$.

\section{Histology}

Xenograft tumors were harvested and placed in fresh $10 \%$ formalin. Tumors were paraffin embedded and $5 \mu \mathrm{m}$ sections were cut and placed on glass slides. Hematoxylin and eosin stain was performed per the manufacturer's instructions (Sigma, Inc.). Identification of macrophages was accomplished by labeling with an anti-CD68 antibody, identification of neovascularization was accomplished by labeling with an anti-CD31 antibody, cell proliferation was identified using a Ki-67 antibody, and apoptosis was identified using Apoptag. Tissue sections were incubated for $10 \mathrm{~min}$ in Citrate buffer, pH6.0 and microwaved. Samples were then incubated with anti-CD68 (DakoCytomation, Inc.; 1:1,000), anti-CD31 (DakoCytomation, Inc.; 1:50), Ki67 (DakoCytomation, Inc.; 1:50), or Apoptag (Chemicon, Inc.) for $30 \mathrm{~min}$ and detected with LSAB + detection/DAB (3,3'Diaminobenzidine; Sigma, Inc.) for $5 \mathrm{~min}$. Slides were dipped in hematoxylin for $1 \mathrm{~s}$ as a counterstain.

\section{Microvascular Density}

CD31 stained slides were viewed at $100 \times$ magnification, representative images were taken, and microvessels were counted. Individual vessels were counted and the data is presented as the averages for each group and expressed as number of vessels per $100 \times$ objective field.

\section{Hemoglobin Assay}

Xenograft tumors were harvested, weighed, and incubated in $1 \mathrm{ml}$ of Drabkin's Reagent and left rocking at $4^{\circ} \mathrm{C}$ for 1 week. Drabkin's Reagent converts the total hemoglobin in a sample to its cyanoderivative, cyanmethemoglobin which can be used to quantify total hemoglobin content in a sample. Absorbance was read at $450 \mathrm{~nm}$, and total hemoglobin values $(\mathrm{mg} / \mathrm{ml}$ per $1 \mathrm{~g}$ of tissue) were calculated from a hemoglobin curve prepared from a standard.

\section{Conditioned Media}

Five lakhs cells per well were plated and allowed to adhere overnight. The following day, media was aspirated off and $1 \mathrm{ml}$ of fresh serum free media was added. Conditioned media was collected either 24 or $72 \mathrm{~h}$ later. 


\section{Endothelial Tube Formation Assay}

In vitro tube formation was performed as previously described [Zhou et al., 2004]. Growth factor reduced Matrigel was diluted with cold serum-free medium to a concentration of $10 \mathrm{mg} /$ $\mathrm{ml}$. Fifty microliters of the solution was added to each well of a 96-well plate and allowed to form a gel at $37^{\circ} \mathrm{C}$ for $30 \mathrm{~min}$. HDMVEC cells $(150,000$ cells/ml) in SF RPMI, RPMI + 10\% FBS, U937 $\mathrm{CM}$, or PC-3 CM were added to each well and incubated overnight at $37^{\circ} \mathrm{C}$ in $5 \% \mathrm{CO}_{2}$. Under these conditions, EC will form delicate networks of tubes that are detectable within $2-3 \mathrm{~h}$ and are fully developed after 8-12 h. After incubation the wells were washed, and the Matrigel and its endothelial tubes were fixed with $3 \%$ paraformaldehyde.

\section{Proliferation Assay}

Cells were seeded at a density of $1 \times 10^{5}$ cells/ $\mathrm{ml}$ for PC-3 cells and $5 \times 10^{5}$ cells $/ \mathrm{ml}$ for U937 cells in a 96 well plate in RPMI $+10 \%$ FBS. Twenty-four hours after seeding, media was changed to either serum free RPMI, RPMI + $10 \% \mathrm{FBS}$, or conditioned media from either PC3 or U937 cells. Cell growth was determined $72 \mathrm{~h}$ later using the WST-1 assay (Pierce Biotech, Inc.) following the manufacturer's instructions.

\section{Cytokine/Chemokine Analysis By Bio-Plex Assay}

Cytokines and chemokines were measured using a human 27-plex cytokine panel (Bio-Rad, Hercules, CA) following the manufacturer's instructions. Briefly, cytokine/chemokine standards were prepared in the same fresh medium that was used for culturing the cells and were assayed in duplicate. To each well, beads coated with antibody to each chemokine or cytokine were mixed with either standards, samples, or a blank in a final volume of $100 \mu \mathrm{l}$ and incubated for $30 \mathrm{~min}$ with continuous shaking ( $300 \mathrm{rpm}$ ) at room temperature. After washing, biotinylated antibodies were added for $30 \mathrm{~min}$ with continuous shaking followed by streptavidinphycoerythrin (PE) for $10 \mathrm{~min}$. The fluorescence intensity of the beads was measured using the Bio-Plex 200 system and Bio-Plex Manager 4.1 software with five-parametric-curve fitting was used for data analysis.

\section{Real Time RT-PCR}

Total RNA was isolated from cell lines using Trizol (Invitrogen Corp.) following the manu- facturer's specifications. Purified RNA (5 $\mu \mathrm{g})$ was converted to cDNA using Super Script II reverse transcriptase (Invitrogen Corp.) following the manufacturer's instructions and used for gene expression analysis by real time PCR using an ABI Prism 7900 HT thermocycler. Primers and probes were purchased from Applied Biosystems, Inc. and used with TaqMan ${ }^{R}$ Universal PCR Master Mix, No AmpErase ${ }^{\mathbb{R}}$ UNG. GAPDH was used as an internal control to normalize and compare each sample. Cycle conditions for real time PCR were $95^{\circ} \mathrm{C}(15 \mathrm{~s})$, $60^{\circ} \mathrm{C}(1 \mathrm{~min}), 72^{\circ} \mathrm{C}(1 \mathrm{~min})$ for 40 cycles. Threshold cycle number for each sample was normalized to GAPDH for that sample and expressed on a log scale relative to GAPDH expression.

\section{Statistical Analyses}

Data was analyzed with GraphPad Prizm software. A One-way-ANOVA analysis was used with Bonferroni's post-hoc analysis for comparison between multiple groups. A Students $t$-test was used for comparison between two groups. Significance was defined as a $P$ value $<0.05$.

\section{RESULTS}

The affects of monoctyes on prostate cancer growth were assessed in vivo using a xenograph mouse model. PBMCs from a normal, healthy adult male and the U937 premonocytic cell line were used. Athymic nude mice were subcutaneously injected with PC-3 prostate cancer cells alone or in combination with monocytes or monocytes pre-stimulated with IL-4 $(10 \mathrm{ng} / \mathrm{ml}$ for $72 \mathrm{~h}$ ). Average weekly tumor growth for each group was determined by weekly caliper measurement for co-innoculation with PBMCs (Fig. 1A) or U937 cells (Fig. 1B). As a control, a group of mice received xenograft implants of PBMCs only or U937 cells only (data not shown). Injection of $1 \times 10^{4}$ PBMCs or U937 cells into athymic mice failed to develop into palpable subcutaneous tumors after 10 weeks. Co-innoculation of athymic nude mice with PC$3+\mathrm{U} 937^{\mathrm{IL}-4}$ cells and PC-3 + U937 cells significantly decreased the time to critical tumor mass $\left(1,000 \mathrm{~mm}^{3}\right)$ compared to PC-3 alone (median time in weeks-PC-3 $+\mathrm{U}^{2} 7^{\mathrm{IL}-4}: 6.5$ weeks, PC$3+$ U937: 7 weeks, PC-3: 12 weeks; $P<0.05$ ) (data not shown). The presence of macrophages in the xenograft tumor bed was confirmed by CD68+ staining (Fig. 1C-H). Interestingly, the 
Craig et al.
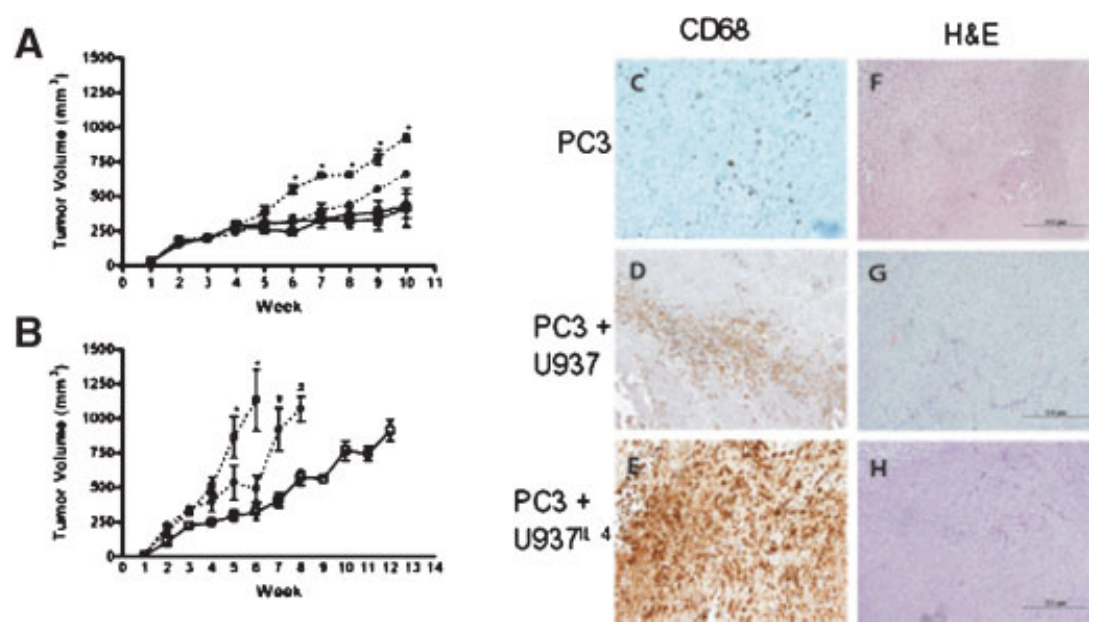

Fig. 1. Co-inoculation of athymic mice with PC-3 and monocytes. A: PC-3 co-inoculated with normal PBMCs. Tumor volumes were monitored weekly by caliper measurement in PC-3 (- $\bigcirc-)$, PC-3 $3^{\mathrm{IL} 4}(-\square-), \mathrm{PC}-$ $3+$ PBMC (- -) and PC-3 + PBMC7 IL4 (-口-). B: PC-3 co-inoculated with U937 cells. Tumor volumes were monitored weekly by caliper measurement in PC-3 (- $\square-)$, PC-3 + U937 (- -) and PC-3 + U937 $7^{1 \mathrm{~L} 4}$ (- - - ). $\mathbf{C}-\mathbf{H}$ : Tumor sections from PC-3 co-inoculation with $\mathrm{U} 937$ cells were analyzed by IHC for the presence of macrophages (CD68) and morphology (H\&E).

PC-3 only xenograft contained CD68+ cells suggesting host (mouse) macrophage infiltration into the tumor bed after inoculation (Fig. 1C).

The presence of TAMs in tumor growth and progression has previously been associated with increased tumor angiogenesis [Crowther et al., 2001]. Thus, the xenograft tumors were harvested after each mouse reached the critical tumor mass, and the affects of co-inoculation with U937 cells on angiogenesis in the tumor environment were analyzed using both the Drabkin's hemoglobin assay and immunohistological staining for CD31 and microvascular density (MVD). MVD analysis revealed a significant increase in vascularization in PC$3+\mathrm{U} 937$ and PC-3 + U937 ${ }^{\mathrm{IL}-4}$ tumors compared to PC-3 only tumors and IL-4 pretreated PC-3 tumors (PC-3 + U937: 292.0 $\pm 143.8, \quad$ PC-3 + $\mathrm{U} 37^{\mathrm{IL}-4}: 380.3 \pm 106.6, \quad \mathrm{PC}-3^{\mathrm{IL} 4}: \quad 106 \pm 40.9$, and $\mathrm{PC}-3$ : $85.5 \pm 38.0 ;$ mean $\pm \mathrm{SD}, P<0.01$ ) (Fig. 2A). Similarly, analysis of hemoglobin content using the Drabkin's assay revealed that co-innoculation of PC-3 cells with U937 cells increased tumor hemoglobin concentration. Specifically, PC-3 tumors had an average concentration $(\mathrm{mg} / \mathrm{ml}$ per $1 \mathrm{~g}$ of tissue) of $1.44 \pm 1.00, \mathrm{PC}-3^{\mathrm{IL} 4} 2.046 \pm 0.76, \mathrm{PC}-3+\mathrm{U} 937$ $7.92 \pm 3.54$, and $\mathrm{PC}-3+\mathrm{U} 937^{\mathrm{IL}-4} 7.37 \pm 4.73$ (mean $\pm \mathrm{SD}$ ) (Fig. 2B). To further assess the role of secreted factors by U937 cells in combination with PC-3 prostate cancer cells on enhanced tumor angiogenesis, conditioned media from U937 or PC-3 cells was used for an in vitro tube formation assay. HDMVEC cells were incubated overnight on reduced growth factor Matrigel ${ }^{\mathrm{TM}}$ and allowed to form a branching network of capillary-like tubes. Incubation with $\mathrm{U} 937^{\mathrm{IL}-4} \quad \mathrm{CM}$ revealed a significant increase $(P<0.01)$ in tube formation as compared to U937 CM, PC-3 CM, and SF media (Fig. 2C).

To address the hypothesis that macrophages work in concert with prostate cancer cells to promote growth and neo-angiogenesis of the tumor, U937 conditioned media was analyzed for cytokine/chemokine expression. PC-3 conditioned media is shown as a control for the cytokines/chemokines that would be present in the in vivo co-innoculation experiments. Of the twenty-seven cytokines/chemokines analyzed U937 cells produce IL-8, IL-9, IL-10, IP-10, MCP-1 (CCL2), RANTES (CCL5), and VEGF at $>1,000 \mathrm{pg} / \mathrm{ml}$ (IL-8: $1,896 \pm 348.2$, IL-9: $1,340 \pm 358.0, \quad$ IL-10: $1,595 \pm 409.5, \quad$ IP-10: $2,254 \pm 689.3$, MCP-1 (CCL2): 4,970 $\pm 1,607$, RANTES(CCL5): $1,560 \pm 465.4$, and VEGF: $5,061 \pm 819.9 \mathrm{pg} / \mathrm{ml}$; mean \pm SD) (Fig. 3A). After stimulation of U937 cells with IL-4 $(10 \mathrm{ng} / \mathrm{ml})$ for $72 \mathrm{~h}$, conditioned media was analyzed for cytokine/chemokine expression. IL-1ra, IL-8, IL-9, IL-10, IP-10, MCP-1 (CCL2), RANTES (CCL5), and VEGF were expressed at $>1,000$ $\mathrm{pg} / \mathrm{ml}$ and significantly elevated compared to 

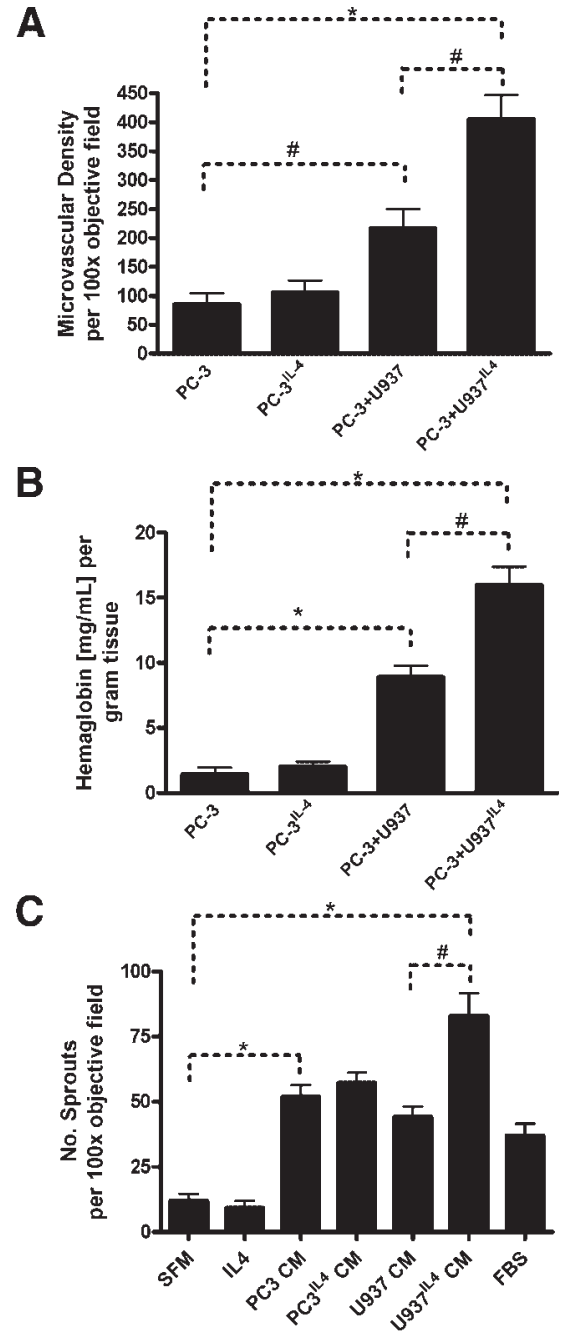

Fig. 2. The presence of $U 937$ cells induces tumor angiogenesis in vivo. Tumor vasculature was identified by IHC analysis of CD31 positive staining (A-C). D: Microvascular density was counted per $100 \times$ objective field from three independent fields per tumor. Data is displayed as mean $\pm \mathrm{SD}$ and significance was determined with a ${ }^{*} P<0.001$ and ${ }^{\#} P<0.05$. E: Hemaglobin content was measured in tumor specimens using the Drabkin's reagent and displayed as the amount of hemoglobin $(\mathrm{mg} / \mathrm{ml})$ per gram of tissue for each tumor (mean $\pm \mathrm{SD}, * P<0.001$ and $\left.{ }^{\#} P<0.05\right)$. F: Tube formation assay on growth factor reduced matrigel using HDMVEC cells was preformed with conditioned media from PC-3, PC- $3^{\mathrm{IL} 4}$, U937, and U937 $7^{\mathrm{IL} 4}$ conditioned media. The number of endothelial sprouts were counted per $100 \times$ objective field from three independent areas and repeated in triplicate. Data is displayed as the mean $\pm \mathrm{SD}$ and significance was determined with ${ }^{*} P<0.001$ and ${ }^{\#} P<0.01$.

U937 cell conditioned media alone (IL-1ra: $1,253.45 \pm 122.92$, IL-8: 3,352.07 \pm 75.14 , IL-9: $2,294.06 \pm 170.51$, IL-10: $2,547.23 \pm 90.86$, IP10: 3,592.7 \pm 82.87 , MCP-1 (CCL2): 7,693.27 \pm 37.31, RANTES(CCL5): $2,595.69 \pm 189.42$, and VEGF: $8,527.14 \pm 615.28 \mathrm{pg} / \mathrm{ml} ;$ mean $\pm \mathrm{SD}$, $P<0.05$ ) (Fig. 3A). PC-3 cells produce high levels of IL-6, G-CSF, and VEGF and low levels of CCL2. Based on these findings, we confirmed MCP-1 (CCL2) expression in the xeongraft tumors from PC-3 only tumors as potential mediators of the increased angiogenesis and tumor growth and compare them to PC-3+ U937 and PC-3 + U937 ${ }^{\mathrm{IL}-4}$ tumors by quantitative real time PCR (Fig. 3B). CCL2 mRNA expression was found to be significantly elevated in PC-3 + U937 and PC-3 + U937 ${ }^{\mathrm{IL}-4}$ compared to PC3 only or PC-3 ${ }^{\mathrm{IL} 4}$ tumors $(P<0.01)$.

Confirmation of the in vivo prostate cancer cell proliferation was seen both by histology and by an in vitro proliferation assay. Staining of xenografts with Ki67, a cell proliferation marker, revealed increased cell proliferation in $\mathrm{PC}-3+\mathrm{U} 937$ and PC-3 + U937 ${ }^{\mathrm{IL}-4}$ tumors (PC$3<$ PC-3 + U937 $<$ PC-3 + U937 ${ }^{\mathrm{IL}-4}$ ) (Fig. 4A-C). There was no significant difference observed in the amount of apoptosis as detected by Apoptag immunohistochemical staining (Fig. 4D-F). Further, to determine if factors secreted by U937 cells influenced PC-3 cell growth in vitro, PC-3 cells were incubated in the presence of U937 CM for $72 \mathrm{~h}$. PC-3 cells incubated in U937 CM (either unstimulated or IL-4 stimulated) demonstrated a significant increase in proliferation compared to the serum free media control (SFM: $0.94 \pm 0.16$, IL4: $0.89 \pm 0.11$, U937 CM: $1.644 \pm 0.25$, U937 ${ }^{\mathrm{IL}-4} \mathrm{CM}: 1.633 \pm$ 0.32, $P<0.01$ ) (Fig. 4G). Additionally, to address the question of prostate cancer celldependent regulation of macrophage cell proliferation, U937 cells were incubated in PC-3 CM. PC-3 CM induced a significant increase in U937 cell proliferation compared to the serum free control cells (SFM: $0.47 \pm 0.01, \mathrm{PC} 3 \mathrm{CM}$ : $0.75 \pm 0.12, P<0.001$ ) (Fig. $4 \mathrm{H}$ )

\section{DISCUSSION}

In order to investigate the role of macrophage infiltration in prostate cancer growth, we established a xenograft model where PC-3 prostate cancer cells were co-inoculated with either normal PBMCs or the U937 premonocytic cell line. U937 cells were originally isolated from the pleural effusion of a patient with histiocytic lymphoma but are not terminally differentiated. The initial experiment (Fig. 1) compared the response of PC-3 prostate cancer cells to co-inoculation with normal PBMCs and U937 cells. PC-3 prostate cancer cells responded similarly to normal PBMCs and U937 cells. 


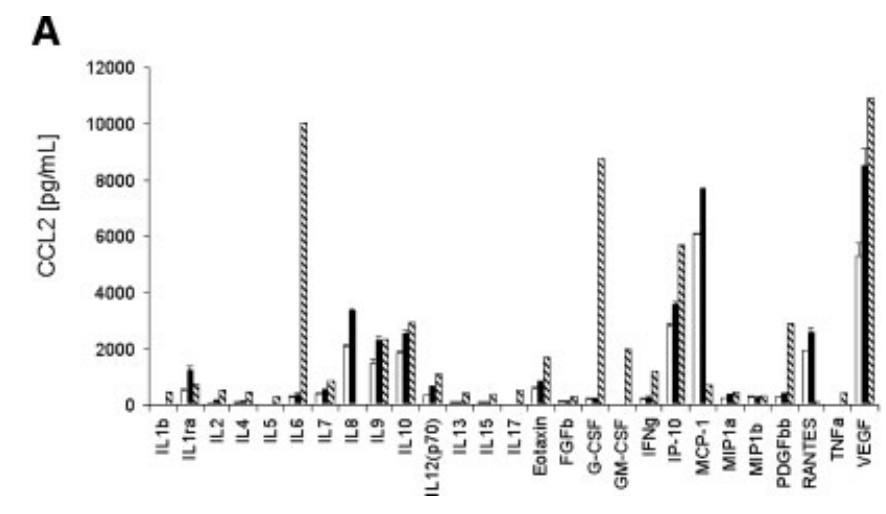

B

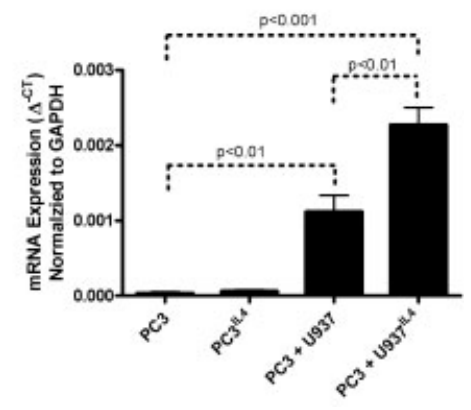

Fig. 3. Stimulation of U937 cells with IL4 induces chemokine expression. A: Analysis of chemokine expression from PC-3 cells (dashed bars), U937 (open bars), and U937 cells stimulated with IL-4 $(10 \mathrm{ng} / \mathrm{ml}$ for $72 \mathrm{~h}$ ) (closed bars) was preformed using a multi-plex assay platform. IL-1 ra, IL-8, IL-9, MCP1 (CCL2), and VEGF were significantly upregulated $(P<0.05)$ after IL-4 stimulation. B: CCL2 mRNA expression in tumor specimens isolated from PC-3, PC-3+U937, or PC-3-U937 $7^{1 \mathrm{~L} 4}$ was confirmed by quantitative real time PCR and normalized to GAPDH levels using the $\Delta^{-\mathrm{CT}}$ method.

Co-inoculation of PC-3 and PBMCs or U937 cells resulted in a significant increase in tumor growth in vivo. Prestimulation of monocytes prior to xenograft implantation resulted in a further increase in tumor growth compared to unstimulated monocytes. Logrank analysis of time to critical tumor mass (tumors $>1,000 \mathrm{~mm}^{3}$ ) revealed a significant trend $\left(\chi^{2}=3.842, P<\right.$ 0.05) in tumors co-inoculated with U937 cells. These data support the hypothesis that the presence of tumor infiltrating monocytes/ macrophages promotes prostate cancer growth.
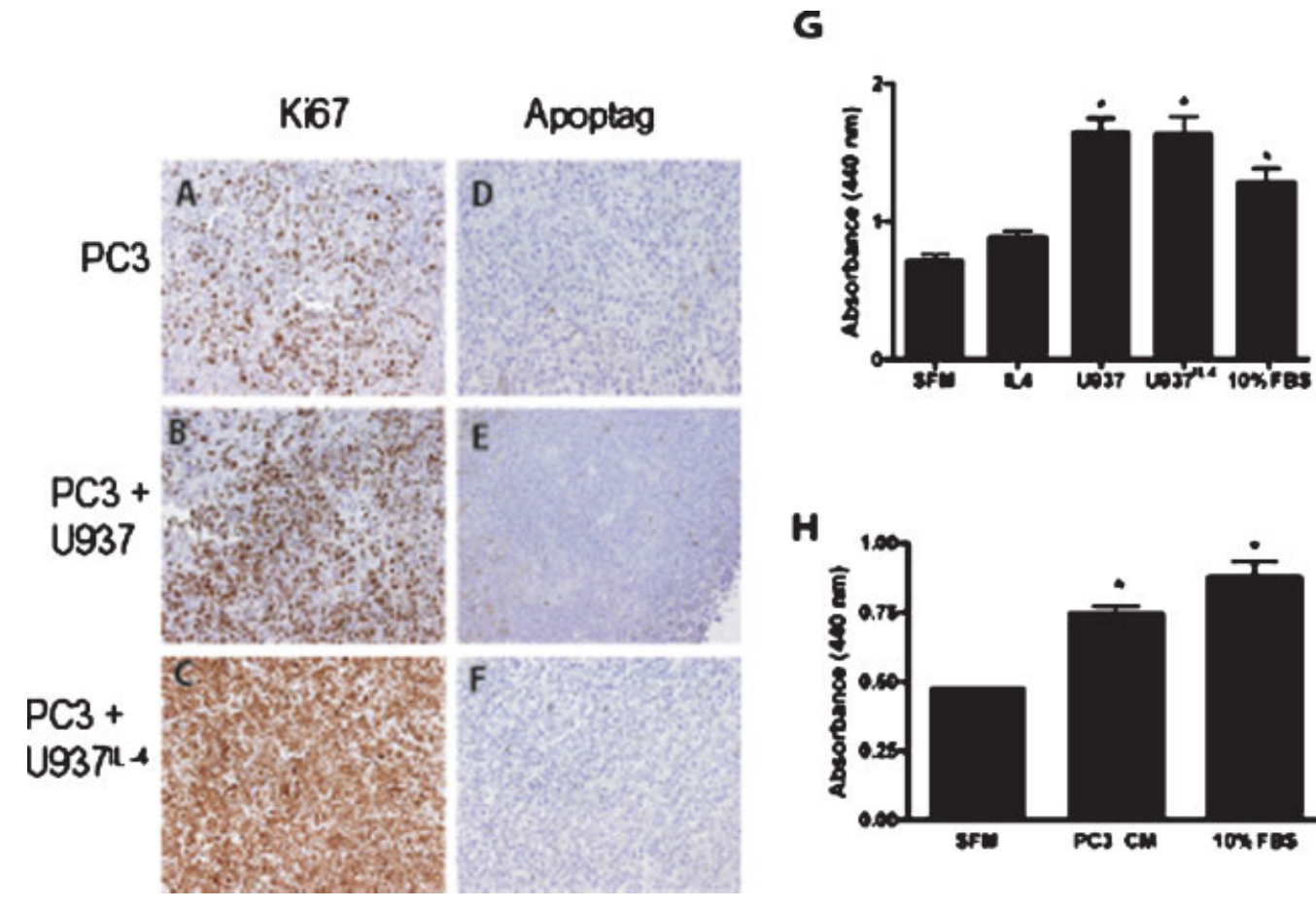

Fig. 4. The presence of U937 cells stimulated PC-3 growth. The effects of U937 cells on PC-3 cell proliferation were analyzed by $\mathrm{IHC}$ for Ki67 staining $(\mathbf{A}-\mathbf{C})$ and apoptosis using Apoptag (D-F). G: In vitro analysis of PC-3 proliferation was determined by WST-1 assay using IL4 $(10 \mathrm{ng} / \mathrm{ml})$, conditioned media from U937 cells or U937 ${ }^{\mathrm{LL} 4}$ cells. Serum free media (SFM) or serum media $(10 \% \mathrm{FBS})$ was used as controls $\left({ }^{*} P<0.01\right)$. $\mathbf{H}$ : In vitro analysis of $U 937$ proliferation was determined by WST-1 assay using conditioned media from PC-3 cells $(* P<0.01)$. 
The difference between tumor destructive macrophages and tumor-promoting macrophages is not clearly understood; however, several reports have suggested that stimulation of recruited monoctyes with IL-4 induces a tumor-promoting phenotype and results in TAM formation [Mantovani et al., 1992]. Prior to co-inoculation, we pre-stimulated U937 cells with IL-4 (10 ng/ml) for $72 \mathrm{~h}$. Surprisingly, no difference in overall tumor growth and time to critical tumor mass was observed between untreated U937 cells and IL-4 treated U937 cells. There was a significant increase in actively proliferating cells as evident by Ki67 immunohistochemical analysis in xenografts comprised of PC-3 + U937 cells compared to PC-3 cells alone. The presence of TAMs in various neoplastic tissue has been implicated in stimulating increased tumor angiogenesis, and this effect on increased tumor vascularity is a prominent feature of tumor-promoting macrophages. Thus, we assessed the vascular content of the xenograft tumors. There was a significant increase in microvascular density (MVD) in tumors from PC-3 + U937 cells compared to PC3 cells alone. Further, pre-stimulation of U937 cells with IL-4 did not significantly increase the amount of neovascularization found within the xenograft tumors. Interestingly, when conditioned media from PC-3 cells, U937 cells, or U937 cells pre-stimulated with IL-4 was used in an in vitro tube formation assay to mimic neoangiogenesis, a significant increase in the number of sprouts (tube formation) was identified in the U937 ${ }^{\mathrm{IL}-4}$ conditioned media. These data suggest that in an in vitro model IL-4 stimulated U937 cells induce angiogenesis; however, in an in vivo model the role of IL-4 may be lost due to additional factors (including endogenous IL-4) present in the xenografts.

In order to understand the role of IL-4 stimulated U937 cells and their potential for influencing prostate cancer growth and inducting angiogenesis within the tumor bed, we collected $24 \mathrm{~h}$ conditioned media from U937 cells and U937 $7^{\mathrm{IL}-4}$ cells and analyzed cytokine/ chemokine expression using the Luminex technology. U937 cell conditioned media contained high levels $(>1,000 \mathrm{pg} / \mathrm{ml})$ of several cytokines (IL-8, IL-9, IL-10, IP-10, MCP1 (CCL2), RANTES (CCL5), and VEGF). Prior stimulation of U937 cells with IL-4 significantly increased the levels of IL-1ra, IL-8, IL-9, MCP1 (CCL2), and VEGF. The role of CCL2 in regulating the migration and proliferation of cancer epithelial cells has been suggested in breast cancer and multiple myeloma [Valkovic et al., 1998; Ohta et al., 2002; Vanderkerken et al., 2002; Lebrecht et al., 2004]. Recently we have reported that CCL2 is elevated in the prostate cancer tumor microenvironment of metastatic lesions [Loberg et al., 2006a] and to influence prostate cancer growth in vitro [Loberg et al., 2006a; Lu et al., 2006] however it remains unclear as to the mechanism of increased CCL2 expression. Currently the role of monocytes on tumor cell proliferation is unclear but our data demonstrates that monocytes, and specifically monocytes stimulated with IL-4, increase the neovascularization of prostate cancer tumors and that CCL2 plays a significant role in regulating monocyte infiltration and vascularization of prostate neoplasias. In addition, these data suggest that stimulation of U937 cells with IL-4 induces a TAM phenotype and upregulates several cytokines and chemokines (specifically CCL2) that are important in prostate cancer tumor growth and that stimulate angiogenesis within the tumor bed.

\section{CONCLUSION}

Although relatively few studies have characterized the differential expression of chemokines and chemokine receptors found on prostate cancer cells and in the prostate tumor microenvironment, it is apparent that chemokines secreted by infiltrating macrophages play a pivotal role in regulating prostate cancer cell growth and metastasis. It is unclear what the predominant chemokine(s) are in the regulation of prostate cancer growth and metastasis, and if they are most influential as direct mediators of tumor cell growth or if their prominent role is regulating the microenvironment within which the tumor cells thrive (i.e., angiogenesis, infiltration of tumor-promoting immune cells, etc) [Lissbrant et al., 2000; Lewis and Pollard, 2006]. Lin and Pollard [2004] demonstrated in breast cancer a positive correlation between poor prognosis and the degree of TAM infiltration [Lin and Pollard, 2004]. These data coupled with our preliminary data demonstrating increased tumor growth with the coinoculation of macrophages in prostate cancer suggest an important role for chemokines and their receptors in prostate cancer metastasis and progression. Further investigations into 
the mechanisms of chemotaxis and migration via chemokine signaling would lead to new therapeutic strategies for cancer.

\section{ACKNOWLEDGMENTS}

This study was supported by SPORE Career Development Award and NIH (5P50CA069568).

\section{REFERENCES}

Crowther M, Brown NJ, Bishop ET, Lewis CE. 2001. Microenvironmental influence on macrophage regulation of angiogenesis in wounds and malignant tumors. J Leukoc Biol 70:478-490.

Hart PH, Bonder CS, Balogh J, Dickensheets HL, Donnelly RP, Finlay-Jones JJ. 1999. Differential responses of human monocytes and macrophages to IL-4 and IL-13. J Leukoc Biol 66:575-578.

Kelly PM, Davison RS, Bliss E, McGee JO. 1998. Macrophages in human breast disease: A quantitative immunohistochemical study. Br J Cancer 57:174-177.

Lebrecht A, Grimm C, Lantzsch T, Ludwig E, Hefler L, Ulbrich E, Koelbl H. 2004. Monocyte chemoattractant protein-1 serum levels in patients with breast cancer. Tumour Biol 25:14-17.

Lewis CE, Pollard JW. 2006. Distinct role of macrophages in different tumor microenvironments. Cancer Res 66: 605-612.

Lin EY, Pollard JW. 2004. Macrophages: Modulators of breast cancer progression. Novartis Found Symp 256: 158-168; discussion 168-172. 259-269.

Lissbrant IF, Stattin P, Wikstrom P, Damber JE, Egevad L, Bergh A. 2000. Tumor associated macrophages in human prostate cancer: Relation to clinicopathological variables and survival. Int J Oncol 17:445-451.

Lu Y, Cai Z, Galson DL, Xiao G, Liu Y, George DE, Melhem MF, Yao Z, Zhang J. 2006. Monocyte chemotactic protein1 (MCP-1) acts as a paracrine and autocrine factor for prostate cancer growth and invasion. Prostate 66:13111318 .

Loberg RD, Day LL, Harwood J, Ying C, St John LN, Giles RP, Neeley CK, Pienta KJ. 2006a. CCL2 is a potent regulator of prostate cancer cell migration and proliferation. Neoplasia 8:578-586.

Loberg RD, Day LL, Dunn R, Kalikin LM, Pienta KJ. 2006b. Inhibition of decay-accelerating factor (CD55) attenuates prostate cancer growth and survival in vivo. Neoplasia 8:69-78.

Mantovani A, Bottazzi B, Colotta F, Sozzani S, Ruco L. 1992. The origin and function of tumor-associated macrophages. Immunol Today 13:265-270.

Negus RP, Stamp GW, Hadley J, Balkwill FR. 1997. Quantitative assessment of the leukocyte infiltrate in ovarian cancer and its relationship to the expression of C-C chemokines. Am J Pathol 150:1723-1734.

Ohta M, Kitadai Y, Tanaka S, Yoshihara M, Yasui W, Mukaida N, Haruma K, Chayama K. 2002. Monocyte chemoattractant protein-1 expression correlates with macrophage infiltration and tumor vascularity in human esophageal squamous cell carcinomas. Int J Cancer 102: $220-224$

Sica A, Schioppa T, Mantovani A, Allavena P. 2006. Tumour-associated macrophages are a distinct M2 polarised population promoting tumour progression: Potential targets of anti-cancer therapy. Eur J Cancer 42:717-727.

Sundstrom C, Nilsson K. 1976. Establishment and characterization of a human histiocytic lymphoma cell line (U-937). Int J Cancer 17:565-577.

Van Damme J, Struyf S, Opdenakker G. 2004. Chemokineprotease interactions in cancer. Semin Cancer Biol 14: 201-208.

Valkovic T, Lucin K, Krstulja M, Dobi-Babic R, Jonjic N. 1998. Expression of monocyte chemotactic protein-1 in human invasive ductal breast cancer. Pathol Res Pract 194:335-340.

Vanderkerken K, Vande Broek I, Eizirik DL, Van Valckenborgh E, Asosingh K, Van Riet I, Van Camp B. 2002. Monocyte chemoattractant protein-1 (MCP-1), secreted by bone marrow endothelial cells, induces chemoattraction of 5T multiple myeloma cells. Clin Exp Metastasis 19:87-90.

Zhou JR, Yu L, Zerbini LF, Libermann TA, Blackburn GL. 2004. Progression to androgen-independent $\mathrm{LNCaP}$ human prostate tumors: Cellular and molecular alterations. Int J Cancer 110:800-806. 